\title{
Intention and Responsibility in Speech Acts
}

\author{
Jesús Navarro-Reyes, University of Seville
}

\begin{abstract}
I have argued elsewhere (Navarro-Reyes 2010) that the kind of excuses that appeal to a lack of intention in the performance of a speech act do not, in general, try to deny that the deed itself took place (i.e., in cases where we say that the act is performed unintentionally, we would not imply that the act was not performed at all, but that it was performed in a particular way). If this is correct, speech acts token performances ought to be defined independently of the speaker's putative illocutionary intentions. In this paper I will pursue this idea by discussing the views of Alston (2000), a prominent champion of the intentionalistic account, who defines speech acts in terms of the notion of "taking responsibility". Unlike Alston, I will claim that 'unheard speech acts' are not a legitimate category within speech acts, whereas cases of 'unintended speech acts' might be correctly considered as legitimate cases of speech acts, since they do effectively change the normative context.
\end{abstract}

\section{Keywords}

speech acts theory, intentional action, responsibility, second person perspective

\section{Introduction}

Should speech acts be defined as intentional actions, i.e. as actions essentially performed with particular intentions? That seems to be out of question in speech acts theory, at least in Austin's (1962) and Searle's (1969) tradition. I do not hesitate that speech acts, as a social practice, must be defined in terms of intentions and, in particular, of illocutionary intentions. With no appeal to those intentions there is no way to understand what the practice is, and no way to distinguish different types of illocutionary acts. But I would like to cast some doubts here about the need to define token speech acts performances in terms of the putative intentions of speakers. In my opinion, it could be legitimate to assert that someone performed a particular speech act, even if in fact she did not have the illocutionary intentions that are usually considered as constitutive of that speech act.

My criticism will focus on Alston's (2000) treatment of two sorts of boundary cases in speech acts theory: unheard speech acts and unintended speech acts. With respect to the former, Alston considers that they are a legitimate category within speech acts. In his opinion, an illocutionary act does take place despite being unheard by anybody. For instance, according to Alston, an utterance that was performed with the intention to make a promise would still be a promise, despite it was not heard by the intended audience, or even by anybody. I will explain the reasons why I think this is wrong, since it implies that Alston's view is too focussed on what has been called 'inner' conditions. 
With respect to the latter, unintended speech acts, Alston's position is the reverse: he tends to assume that, in so far as the utterance was not performed by the speaker with some specific illocutionary intention, the alleged speech act did not take place at all. In his view, the unintended speech act would only be an apparent speech act: something wrongly considered as a speech act by the audience, but that, in so far as it was unintended, would not have taken place at all. I will also disagree with Alston on this point, and I will defend that unintended speech acts are a legitimate category of speech acts: a crucial possibility that must be considered in the definition of token - or individual-illocutionary acts. The truth is that Alston's position in this respect is not very clear: in the first place, he doubts that unintended speech acts are even possible at all. In his view, illocutionary acts are essentially intentional actions. However, in case unintended speech acts were ever possible, Alston considers them as so fringe and marginal possibilities that he does not find them relevant enough to modify the core of his theory. Intention, for Alston - as for most speech acts theorists-, is constitutive of each and every illocutionary act performance. In contrast to this, I will defend that intentions are constitutive of the practice of speech acts, but not necessarily of each and every performance within that practice. We need to introduce intentions into our account if we want to define illocutionary acts types, but we should not introduce them as necessary conditions to identify illocutionary act tokens. In other words: intentions do not have to be necessarily part of the scene, in order to have a case of fully committing illocutionary act performance.

The point of view that I will defend, as we shall see in the end, denies that the first person point of view should have the last word in determining the occurrence of speech acts. On the contrary, I will defend that it is the second person point of view-i.e., the point of view of the hearer - that should have that last word, despite it is - and must be - epistemically limited. From the hearer's limited perspective, she might have the right to assert that a particular illocutionary act took place disregarding the effective occurrence of intentions by the part of the speaker. The key to guess if a particular speech act did effectively take place is not to be found in the speaker's mind, but in the legitimate expectations that the utterance created in the hearer's mind. These expectations are linked to the attribution of intentions to the speaker but, in the last resort, what makes the utterance count as a speech act is not the effective occurrence of those intentions, but the legitimacy of the hearer's attribution of those intentions.

In order to show the relevance of this discussion, I will briefly sketch the rise of the problem in Austin's and Searle's accounts, before getting to Alston. 


\section{Approaching the problem}

\section{Austin's Hippolytus and the risks of the first person perspective}

I think we have to thank Gazdar (1981: 68) for the one that might be the simplest and clearest formalization of what a speech act is: "a function from contexts into contexts". By uttering some words, the speaker changes the social context and, in particular, she changes its normative conditions. E.g.: at $\mathrm{t}_{1}$, before I made my daughter the promise to bring her to the park, I was not obliged to bring her to the park. At $t_{2} I$ utter the words "I promise to bring you to the park", which she hears and understands. Because of that, at $t_{3}$, I am obliged to bring her to the park. Why did the normative situation change between $t_{1}$ and $t_{3}$ ? Why do we say that I have a normative reason to do something at $t_{3}$, which I did not have at $t_{1}$ ? Gazdar's definition is a good description of what happened, but it is not an explanation. The question is: why does the context change at all, just because I uttered some words?

Austin was clearly right when he claimed that making a speech act is something more than just uttering some words. Disagreement arrives when we try to define what this 'something more' is: i.e. the kind of conditions that turn the mere utterance of some words into fully fledged — and morally committing — speech acts. It seems to be out of question that there must be some kind of external conditions about the surrounding context of the utterance: words ought to be uttered in a certain way, in front of a pertinent audience, maybe according to some pre-established conventions, or at least some shared linguistic knowledge. ${ }^{1}$ Furthermore, most scholars agree on the need to include some sort of internal or cognitive requirements, such as that the act had been done with specific illocutionary intentionsthe intention to promise, to threat, or to make a statement-, or that the speaker was aware of at least some of the consequences of her own words. It seems that the utterance must have been done voluntarily, consciously, and intentionally, or on purpose, and it is usually alleged in favour of this that the lack of those internal conditions gives rise to different kinds of excuses, which could finally not make it sensible to require from the speaker to be committed to her words. E.g., by claiming that it was not my intention to promise, I would try to show that I am not committed to my own words - i.e. I would try to show that my words did not effectively change the normative situation. From this point of view, unintentional promises would not be real promises, but just some sort of misleading situation: something that looked like a promise, so to speak, from the outside. Promises made without the intention

1 I will mostly use the concept of "context" as referring to a set of external and internal conditions of the utterance, not in Sperber \& Wilson's limited sense, as "a psychological construct, a subset of the hearer's assumptions about the world" (1986: 15). The way I will use the term-which coincides, I think, with Harnish's recent discussion on the conditions of speech acts (2009: 10)—will be wider, since it does not only include those assumptions, but also many other features. 
to promise would not be a kind of promise; in fact they would not be promises at all.

However, Austin was quite reticent to introduce internal conditions in his account because he considered that this would show speech acts as a sort of inner performances that would only indirectly take place in the public scene. If we accepted that there are some sort of internal or mental necessary conditions for the performance of a speech act, we would seem to buy too that there is something in the mind of the speaker, hidden to the hearer, which precludes us from certainly know weather the speech act did effectively take place or not. In Austin's views, speech acts are social acts: they take place in the social environment. The problem is that, if their performance depends constitutively on the existence of inner hidden mental states, which are only accessible to the speaker herself, then we seem to loose that social character. Speech acts would run the risk to become something the speaker makes inside his mind, where the external manifestations would only be contingent and accessory symptoms of that 'spiritual' private action.

Austin's fears are personalised in the character of Hippolytus, who denied to be bounded to his words because they had allegedly not been uttered with the intention to perform a committing speech act. We find Hippolytus at $t_{3}$, after the occurrence of an utterance that the audience had considered as a promise, claiming that that utterance had not been made with the intention to bind: "An oath my mouth made, but not my heart". If this escape were possible at all, then the whole system of speech acts would melt away like snow under the sun. If words could not bind unless they were accompanied by inner commitments, and inner commitments are never present in the public scene, then they loose the important role that they have in the working of social, stable systems of collaborative actions. It is thus a crucial task for speech acts theory to give an account that would prevent bad faith users of language from escaping their duties. This is not just a matter of fringe or marginal cases, but probably the more fundamental mission that speech acts theory could ever have.

On the other side, Austin is aware that intentions must somehow be part of the story: if promises were never done with the intention to be committed to words, the practice of promising would loose its point. It seems that I made a promise because I intended to be bound by my words-i.e., I intended to change the normative context, in order to grant the hearer a certain right over my future actions. By the same token, whenever I order something, I intend the hearer to be forced to do what I say. Whenever I apologise for something, I intend to show my regret about what I did. What could be the point of speech acts, if they did not express those illocutionary intentions?

So we seem to be divided between two incompatible requirements, and both of them seem to be quite sensible: on the one hand, we have to define illocutionary acts through external conditions, since they would otherwise be detached from the social environment where public duties are established. If those external conditions 
were not fully determinant, we would be blind when trying to ascribe duties and commitments to others, and that would always leave an open door to Hippolytus and those of his kind. On the other hand, we need to define illocutionary acts through internal conditions, since their very performance seems to be non contingently linked to the effective intervention of our mental states. If those mental states were not involved, speech acts would seem to be empty. Speech acts without real intentions do not even seem to be speech acts, but just something that resembles them 'from the outside'. If some necessary conditions were purely internal, we would be blind in the adscription of illocutionary acts to others; if all necessary conditions were external, speech acts would be empty, and the practice would be deprived of meaning. ${ }^{2}$

\section{Searle and his disdain for merely epistemological problems}

Dealing with this tension is a must for speech acts theoreticians. In general, they try to sort it out by combining internal and external conditions in their accounts. Searle's (1969) classic theory might be the best example. He defines what a promise is describing both what happens on the inside and on the outside of the minds of the speakers. In his view, speech acts must be performed with particular intentions, which are constitutive of what those acts are-i.e., those acts would not be what they are if those intentions were not in their origin. And, at the same time, it is the external character of the utterance what makes it count as a speech act in the context where it takes place. This is possible because speech acts are governed by what Searle calls "constitutive rules", which always have the structure: $x$ counts as $y$ in $C$ -i.e., an utterance of a certain kind counts as the performance of a particular illocutionary act in its context. ${ }^{3}$ If the speaker is aware of this constitutive rule, and her

2 Although this tension is important in Austin's work, his famous doctrine of the infelicities does not confront it at all (1962: 14). The situations that he considers as fringe or marginal are always cases where the speaker performs the utterance with the intention to make the speech act, but some conditions are not met up to the point that the act was purported but void (misfires) or professed but hollow (abuses). But what would Austin have to say about cases in which a speaker did not intend to perform a speech act, but her audience was well justified to consider that she had performed it? Would that be a kind of 'infelicity'? If that internal condition was not met, did the very act ever happen at all? What would be, according to Austin, the status of unintended speech acts?

3 The way this account relies on pre-established conventions has been criticised in some famous occasions-such as in (Strawson 1964) or (Sperber \& Wilson 1986: 244). Those accounts rely on inferential processes to do without conventions-beyond basic linguistic ones. But I do not believe that this makes any essential difference with respect to the point that I would like to make. In any case, even if constitutive rules depended on inferential processes, it would still seem that those processes would somehow have to be externally justified. In other words: the inferential basis must be publicly accessible, since it is what makes it legitimate for a hearer to take $\mathrm{x}$ as counting as $\mathrm{y}$ in $\mathrm{C}$. 
action is intentional and effective, she intends to make $\mathrm{x}$ count as $\mathrm{y}$ in $\mathrm{C}$. Both internal and external conditions are met there, in ideal conditions.

The question we could address to Searle would then be: what happens when only one of those two sorts of conditions is met? In particular, what happens when $\mathrm{x}$ does count as $\mathrm{y}$ in $\mathrm{C}$, but $\mathrm{x}$ was not performed with that intention? Would we still have here a case of an illocutionary act or not? E.g.: would an unintended promise be a sort of promise - involuntary made, but still fully committing-, or would it not be a promise at all? ${ }^{4}$ And, alternatively, we would also have to ask what happens in cases where the intention is not fulfilled through the performance: cases in which the speaker intends $\mathrm{x}$ to count as $\mathrm{y}$ in $\mathrm{C}$, but she is, for instance, unheard by the intended audience.

Searle would probably claim that those are merely epistemological questions. We know that both internal and external conditions are met in 'normal' speech acts. And the core of his theory is about those normal conditions. Extraordinary situations should not affect the core of the theory, since we all know what an ordinary promise is, and it is this intuition what is developed through the systematic study of 'linguistic characterizations' (1969: 4). In real life, we might don't know, in particular cases, if some of those conditions are met: maybe $\mathrm{x}$ does count as $\mathrm{y}$ in $\mathrm{C}$, although the speaker did not intend it to be so. But from the fact that we might not be sure it in particular cases, according to Searle, nothing interesting follows about the nature of the practice, which necessarily involves both aspects. In his opinion, speech acts theory should be made from the point of view of God, where all the aspects of the context would be transparently present, including the minds of the speakers.

However, I would like to discuss the convenience of those claims. The truth is that, in real life, speech acts should hold up even in God's absence, or at least in God's silence: what shall we then say from our point of view, which is-and will always be-epistemically limited? In particular, it could be alleged that, from the point of view of human speakers, the internal cognitive states of others are never part of the shared context. At least that is what Hippolytus seems to claim: that we only saw his words, uttered by his tongue, but not his heart or his soul, which had quite different intentions. In cases like this, we have two inconsistent candidates to determine the effective occurrence of the act: the alleged intentions of the speaker on the one hand and the external constitutive rules on the other. We find both that $\mathrm{x}$ counts as $\mathrm{y}$ in $\mathrm{C}$, and that the speaker claims that he did not intend $\mathrm{x}$ to count as $\mathrm{y}$ in

4 It might be important to point out that I am not referring here to cases of insincere speech acts - such as insincere promises, where the promisor would not have the intention to fulfill the promise. Even in cases like this, as Searle's discussion correctly shows (1969: 62), it seems that the speaker should somehow have the intention that her utterance will make her responsible for intending to perform the promised action. It is the lack of this second order intention what bad faith users of language, such as Hippolytus, could always deny to have had. 
C. In cases like this, Searle's theory eludes the problem, considering it as merely epistemological. But it could hardly be ignored, unless we are happy to leave our theory out of the realm of real life.

\section{Alston and the act of taking responsibility}

In contrast to Searle, who seems to avoid the problem, William P. Alston (2000) has tried to give it an answer. In his view, an illocutionary act is necessarily the effect of an intended action. This intended action is what he calls " $R$ 'ing", which stands for "taking responsibility for the satisfaction of a condition" (2000: 54). According to Alston, R'ing is something that the speaker does: not just something she realises or assumes, or something that happens to her, but an action that must be conscious and intentional, in order to be the sort of action that it is. ${ }^{5}$ The active character of this intentional action involves the utterer's instituting a state of affairs, rather than just being a matter of the utterer's recognizing an already existing state of affairs, or assuming it.

That would mean that, if a speaker $(\mathrm{S})$ promised a hearer $(\mathrm{H})$ that he would bring her to the park, then $\mathrm{S}$ took responsibility (R'd) for bringing $\mathrm{H}$ to the park. And if $\mathrm{S}$ was not taking responsibility for bringing $\mathrm{H}$ to the park, $\mathrm{S}$ did not promise $\mathrm{H}$ to bring her to the park. Whatever he uttered, without the intention to take that responsibility there would be no illocutionary act. This intention would be constitutive of the act up to the point that, in its absence, there would be no such act. Promising would not just be uttering some words, but R'ing in uttering them. The speaker's intentional action of R'ing would be the reason why Gazdar's function applies, and normative contexts change with the occurrence of speech performances.

According to Alston, we rely on the external conditions in order to recognise those internal intentions. If $\mathrm{x}$ counts as $\mathrm{y}$ in $\mathrm{C}$, it is because we know that, by uttering $\mathrm{x}, \mathrm{S}$ was R'ing. Looking for the speaker's intention to $\mathrm{R}$ is looking for the very occurrence of the illocutionary act. Providing conclusive evidence that $\mathrm{S}$ did not intend to $\mathrm{R}$ would eo ipso mean that $\mathrm{S}$ did not perform any illocutionary act at all.

This is the view that I would like to confront. In what follows, I will try to show that this account does not work because what makes a community consider an utterance as a committing speech act is not the presence or absence of that act of $\mathrm{R}$ 'ing by the part of the speaker in the moment of the utterance, but the way the utterance itself was performed with regards to the set of expectations that were justly generated by it in the audience. In my view, it is the uptake of hearers-at least the one that is legitimate, according to the circumstances-what would be constitu-

5 Moya (1990: 38-48) seems to defend a similar point from the philosophy of action. He does not talk about speech or illocutionary acts, but about "symbolic acts", which he defines as necessarily implying the intention from the part of the agent. I believe that most of what is said here about Alston might also be applied, mutatis mutandi, to Moya's account of symbolic acts. 
tive of the act itself. If I am right, the act would still be in order even if we didn't know if the speaker had the intention to $\mathrm{R}$. What is more: the illocutionary act would still be such an act even if we finally knew that the speaker was not intending to R. Recognising the intention to $\mathrm{R}$ would then not be the same as identifying the effective occurrence of the illocutionary act.

I think that Alston is right in considering responsibility as the key concept in the definition of illocutionary acts, but I don't think that the speaker's take of responsibility is the crucial point. I would say that the key is not in the assumption of responsibility from the first person point of view -i.e. the point of view of the speaker - but the attribution of responsibility from the second person point of view -i.e. the point of view of the hearer. The necessary conditions for the identification of a speech act are not to be found in the first person point of view of the speaker, who allegedly made herself responsible for her words, but from the second person point of view of the hearer, who legitimately made the speaker responsible for her utterance. I will thus try to defend that token speech acts do not hold up because we make ourselves responsible for what we say when we say it, but because we are made responsible for what we have said, once we have said it.

\section{Confronting the problem in Alston's account}

It might be easier to understand the difference between Alston's views and the ones that I am proposing by considering how could we paraphrase the following question: did the speech act take place? According to Alston, we could replace this by the question: did the speaker R? In my view, the correct paraphrase would be: was the hearer sufficiently justified to attribute the intention to $R$ to the speaker? The difference is important because the hearer could be justified, but wrong. I.e. he could have very good reasons to attribute to the speaker an illocutionary intention, even if the speaker did not have it at all. ${ }^{6}$ If that is correct, we could find situations in which the speech act took place, despite the absence of illocutionary intention by the part of the speaker. Those would be cases of unintended speech acts, and I will try to show that they are genuine attributions of speech acts. Alternatively, even if the speaker R'd intentionally, in my view the speech act did not take place if the hearer did not have — or was not aware - of good reasons to attribute to the speaker the intention to R. Those would be cases of unheard speech acts, and I will claim that they are not genuine attributions of speech acts. The difference between Alston's views and the ones that I propose can thus be tested in these two sorts of marginal, fringe cases.

6 I am assuming here a point that is generally accepted in epistemology: that somebody could be justified in believing $p$, even if she could be wrong. " $\mathrm{S}$ is justified to believe $p$ " does not imply that $p$ is necessarily true. 


\section{Are there unheard illocutionary acts?}

In contrast to both Austin and Searle, Alston considers that the illocutionary act does take place disregarding the audience uptake, understanding, or even hearing of the utterance. This is his reason to refuse Searle's requirement of "normal conditions of input and output" in the performance of promises. According to Alston, e.g.:

it is not necessary for promising [a hearer] $\mathrm{H}$ that I will do [an action] $\mathrm{A}[\ldots]$ that $\mathrm{H}$ understand what I said. To be sure, if $\mathrm{H}$ did not understand me, she didn't realize that I made that promise, but I could still have done it. Suppose that I mistakenly think that $\mathrm{H}$ heard and understood me. I show up to take $\mathrm{H}$ to the meeting, and $\mathrm{H}$ is surprised at this. I might well say "Didn't you hear me when I promised to take you?", thereby presupposing that I did promise this even if H didn't realize it (Alston 2000: 53).

Therefore, according to Alston, an unheard promise is a promise, as far as the act of R'ing took place, unbeknownst to the hearer. Alston is aware that this is a thorny point, since it could seem that he is turning the speech act into something that takes place in absence of any social frame. He thus has to qualify later his position, along the following terms:

the possibility of a normative state of affairs being initiated by [the utterer's] U's R'ing that $\mathrm{C}$ depends on the existence of a system of rules that is in force within a community that includes U. [...] When U R's that $\mathrm{C}$ in performing an illocutionary act, that is not a purely private performance that could be what it is regardless of how it engages the surrounding community. For R'ing consists in making certain kinds of reactions by others appropriate (Alston 2000: 58).

However, as I will try to show, this clarification does not seem to be enough to exonerate Alston from the accusation of considering speech acts as private performances, which only accidentally take place in the social scene.

But let's follow his argument for a moment. We are dealing with a situation in which $\mathrm{S}$ believes that he made a promise to $\mathrm{H}$, but $\mathrm{H}$ did not hear it. $\mathrm{S}$ believes that a promise was made, but $\mathrm{H}$ does not. Who would be wrong there? According to Alston, it is $\mathrm{H}$ who is mistaken, since $\mathrm{S}$ did take the responsibility for her words, whether $\mathrm{H}$ heard them or not, and whether $\mathrm{H}$ recognised her intentions or not. In Alston's opinion, the promise was performed, despite the fact that nobody noticed it, because $\mathrm{S}$ would have succeeded in making certain kinds of reactions appropriate- disregarding the fact that those who could have benefited from this normative change knew it or not. If $\mathrm{S}$ had not shown up to take $\mathrm{H}$ to the meeting, then $\mathrm{H}$ would have been in a good situation to recriminate this to $\mathrm{S}$, whether she knew or not that she was in such a position. And $\mathrm{S}$ would still be exposed to such criticism, according to Alston, because she did perform her speech act, although it was not heard by anybody.

Pace Alston, I would say that it is S who would be wrong in this imagined case. Not the unhearing promisee, but the unheard promisor. In my view, the promise would have not taken place, since it was unheard by anybody. In my opinion, 
the correct way to describe the situation is to say that $\mathrm{S}$ intended to make a promise, but failed to do so. The reason is that, by describing the situation this way, we preserve the difference between an intended but defective act, and an effectively performed one. Imagine $S$ fails to accomplish what she thought she had taken the responsibility to do-i.e., she fails to perform the promised act. Full with regret, she cannot take out of her head the idea that she has let $\mathrm{H}$ down. But then, in a further conversation, she realises that $\mathrm{H}$ did not hear the promise. In that case, $\mathrm{S}$ could feel relief quite happily: she was lucky at the end, since although she tried to put herself under the responsibility to do $\mathrm{C}$, she failed to do so, without noticing it. She could correctly recriminate herself for not doing what she thought was her duty (and she certainly should think about it twice before making any other promise), but this regret would not be the result of the actual breach of any social obligation, because such an obligation would not exist. In Gazdar's jargon, there would have been no change in the normative context because of S's utterance.

In cases of unheard illocutionary acts, we have two conflicting sets of beliefs: $\mathrm{S}$ believes that she has made a promise, whereas $\mathrm{H}$ believes that no promise took place. Both cannot be right at the same time. Alston would claim that it is S who is right, because he R'd - and this would be a relevant fact, unknown by H. I would agree that S R'd but, in my opinion, it is $\mathrm{S}$ how lacks a relevant piece of knowledge - that her utterance was not heard by H. So both of them are in epistemically limited situations: both of them lack some significant piece of knowledge. This is the reason why the problem is epistemological, and it does not show up from Searle's perspective, since he intends to describe the situation from God's point of view. But my intention is to face the problem from the epistemically limited situations of the contenders, in order to determine if the normative context did change or not-i.e. if Gazdar's function applies or not. And my opinion is that it does not apply, since the speaker's obligation is not effective-although, for a certain period of time, he believes it is. And, with no change in the normative context, no function would apply, and no illocutionary act would take place. An unheard illocutionary act would not be a kind of illocutionary act, but a failed one, a fake one: something that merely resembles an illocutionary act, so to speak, 'from the inside'-i.e. from the point of view of the speaker. Why giving the priority to the hearer's point of view? I would like to return to this question at the end of the paper.

\section{Unintentional illocutionary acts}

According to Alston, in performing an illocutionary act, $\mathrm{S}$ would not only $\mathrm{R}$ that $p$ is the case, but also intend her act to count for $\mathrm{H}$ as such an intentional action. The crucial point of R'ing is both that it is intentional, and that its performance has the intention to be recognised as intentional - following in this the tradition of Grice. Alston is thus very reluctant to accept that an unintentional illocutionary act could 
be ever conceivable. After considering some examples, he finally does accept that possibility, but he expresses his doubts that those are cases of a fully fledged speech acts; and, most importantly, he restricts the conditions of his examples in such a strong way that they become really eccentric cases, which would not force him to reformulate his theory in order to accommodate them. I will try to show in detail that his way of twisting the examples is somehow confusing and biased.

Alston considers three couples of examples of actions that seem to be candidates for a legitimate category of unintentional illocutionary acts: firstly, cases of slips of the tongue and linguistic ignorance; secondly, cases where the hearer did not grasp the deviant intentions of the speaker, although he legitimately expected those deviant intentions to be grasped; and thirdly, cases where the speaker did not give any clue of any kind of his own deviant intentions. I will confront those three kinds of examples in turn.

\section{Slips of the tongue and linguistic ignorance}

In the first group of examples, the speaker produces her sentence voluntarily in order to perform a certain illocutionary act, but the utterance is inadequate for this intention. Although $\mathrm{S}$ intended $\mathrm{x}$ to count as $\mathrm{y}$ in $\mathrm{C}$, $\mathrm{x}$ does not count as $\mathrm{y}$ in $\mathrm{C}$ at all, but as z. From the hearer's point of view, it seems that $\mathrm{S}$ did z; but $\mathrm{S}$ did not have that intention-i.e., her action could not be described as intentional under that description. In cases like this, Alston claims, we would be wrong in claiming that $\mathrm{S}$ did $\mathrm{z}$, because $\mathrm{z}$ is described as an intentional action-i.e. as an illocutionary act, whose illocutionary intentions are constitutive-, and as far as S did not have the intention to do $\mathrm{z}$, she did not do it.

However, in my view, slips of the tongue, for instance, are clearly cases in which the speaker does say whatever she said, and do whatever she did, although she allegedly did it unintentionally. E.g., if her words were outrageous or inappropriate, the hearer would have the right to recriminate her for them. Just like you would not step less strongly on someone else's foot just because you did it unintentionally, you would not perform a less committing speech act just because you thought that you were doing something else, or because you did not realise exactly what you were doing. The unintended character of the act does not make the act vanish away: it only allows us to qualify it in a particular way, making a certain sort of excuses valid: instead of excusing herself by saying, e.g., that her unjustified utterance was the result of a state of nervousness or anger, in cases of slips of the tongue $\mathrm{S}$ would do so by claiming that the speech act that took place was not the one she was intending to produce. In any case, the act was performed, and if it was inappropriate, it would require an excuse, precisely because it did happen. In this sense, there is an important difference between claiming that whatever the hearer understood, that was not what the speaker said, and claiming that what the speaker actually said was not what she was intending to say. Claiming that she did not in- 
tend to say it is completely different from claiming that she did not say it at allsee.

On the other side, a lack of linguistic knowledge by the part of the speaker would not prevent the utterance from having illocutionary and perlocutionary effects. The problem here is that Alston's examples are carefully selected in order to present cases where the resulting act would be impossible, or absurd:

A friend who had spent a sabbatical in Florence reported going into a grocery and asking for a dozen "oggi" (todays), intending to have been asking for a dozen eggs ("uovi") (Alston 2000: 137).

Of course, in that case we could hardly say that a fully committing speech act ever took place; however, the reason is not that the speaker did not intend to order a dozen "todays", but that ordering a dozen "todays" is a meaningless action-and even a grammatical mistake. It is not the lack of intention what prevents the act from being fulfilled, but the request's grammatical incoherence.

Let me thus propose my own example: imagine I order a full English breakfast in a restaurant believing that I am ordering a continental breakfast, just because somebody told me that a "full English breakfast" is usually composed by a croissant, a juice, and a coffee; when the waiter brings me a plate with eggs, sausages, beacon, baked beans, tomatoes, mushrooms and toasts, I am astonished, and I deny that that was what I had ordered. However, it is me who is completely wrong, not the waiter, since that was in fact what I had ordered. Only if the owner is kind enough to exonerate me from the consequences of my speech act, will I be exempted to pay what I in fact ordered. And this is so because it is not my intention what makes the utterance count as an illocutionary act: what makes my utterance be an case of the constitutive rule is not my intention, but the performance itself.

This first group of examples of unintended acts proves a very simple point: the performance of the act is defined by what I uttered, not by my intention in uttering it. If I could somehow prove that I did not have that intention, and convince the hearer that it was a slip of tongue, or a linguistic confusion, I would still rely on her benevolence to accept my excuses. It is a matter of good manners to do so, but in the last resort, the hearer might have good reasons not to accept my excuses-all the stuff that is included in a full English might cost a fortune!-, and she would have a right to do so, since it is me who would be in debt because of my words. What makes Gazdar's function work in any particular occasion is not the specific intentions of the speaker in that occasion, but the way the utterance itself is performed - intentionally or not - according to some constitutive rule.

\section{Non-grasped deviant intentions}

But of course, the kind of illocutionary act S performed is not just determined by the meaning of the words - or their illocutionary act potential, in Alston's jargon: we must also take into account the context of the utterance. And that is what, ac- 
cording to Alston, makes the difference in the second group of cases. Giving the example of a guy who tests a microphone by uttering "I am going to become a hermit", Alston claims that the speaker is not committed to the act he announces, just because somebody in the audience did not realise that he was just testing the microphone. Would this be a case of an 'unintended avowal'? The answer is no, in Alston's opinion, since the intentions of the speaker that are constitutive of the avowal-his intention to $\mathrm{R}$, and to make his own utterance count as such intention for others-would be absent from the scene.

Now again, the absurdity of Alston's example predisposes us to deny that the unintended act ever took place. It is plain that the speaker would not be committed to become a hermit, but not because he did not have the intention to be bound by his words, but because committing oneself to become a hermit is quite a weird thing to do in a concert, just like that, in front of thousands of strangers, coming out of the blue. But imagine that the sound technician had uttered the words: "Ladies and gentlemen, I'm afraid that the concert has been cancelled. You will be refunded the cost of the tickets on the way out". Well, in that case, the guy would have probably lost his job! However, if words were just being mentioned by him, but not used, and the utterance itself would thus be deprived of intentionality, why should it matter at all what he said? Both the "I am going to become a hermit" utterance and the "the concert has been cancelled" one allegedly lack any communicative intention whatsoever, since both were just uttered to test the sound system. The difference is not in the intention of the speaker, which could be exactly the same, but in the kind of response that would be legitimately expected. The speaker himself would probably expect that uptake, but he does not have to expect it in order to make it legitimate: the legitimacy would be determinate by the utterance and its context, independently of the speaker's awareness of this legitimacy, and even of the speaker's illocutionary intentions. The sound technician would give a poor excuse if he said that he expected everybody to be aware that he was just testing the microphone: he did in fact announce that the concert was cancelled-he might have done it unintentionally, if he's sincere and clumsy enough, but he did it anyway.

Alston tries to show that the speech act does not ever take place, unless it is accompanied by the speaker's illocutionary intention to R. But in his example the reason why the audience is not legitimated to attribute the speech act to the speaker is not that the speaker did not have the intention to $\mathrm{R}$, but that the resulting utterance, in that context, would not be enough to legitimate the audience to attribute the illocutionary intention to the speaker. If the content of the utterance were correct and appropriate in the hearer's context, that legitimacy would not depend on the effective existence of the intention by the part of the hearer. 


\section{Non-communicated deviant intentions}

We finally face the third group of examples: cases in which the speaker means something completely different from what her words mean, but does not give any clue whatsoever of this being so. Alston's strategy of turning the examples into eccentric situations that could not be taken seriously is here clearer than ever before. I will focus on his example of a groom who says, "Yes I do", intending to mean "It's hot in here". In Alston's example, the groom would later claim that he was using a private code, although nobody was aware of that. Alston specifies here that:

We must be clear that [the example] does not involve the following features: (1) The groom cracks under the strain and temporarily loses contact with his surroundings, thereby failing to realize that he was participating in a marriage ceremony [...]. If that were the case, he was performing no illocutionary act at all, intentional or unintentional (Alston, 2000: 140).

Well, this is quite disputable. To begin with, most of the things the groom could do during his alleged trance would probably be considered as unintentional actions, and it would hardly make sense to say that they were not actions at all, but merely events. V.g., if he began to tell an inappropriate joke to the bride's father, we would probably agree that he did not do it intentionally, or even consciously, but it is obvious that he did do it, although unconsciously - unless we want to assume that he did not do anything at all, but just his body, or his mouth, or that the joke that was told was not told by anybody, which would be quite a weird way to describe what happened. What would then prevent us from saying that he did perform an unintentional illocutionary act if, instead of telling the joke, he had answered: "I do"? Depending on the behaviour the groom shows during his alleged trance, we would be inclined to say that his illocutionary action was intentional or unintentional, conscious or unconscious, but in any case we could not deny that he did perform the act. If he seemed dazzled and confused, and mechanically uttered the words "I do" while he was staring at the infinite, we would probably assume that his actions were being performed unintentionally, and we would be quite prone to excuse him if he claimed that he was not aware of what he was doing. But if he seemed awake an relaxed, he looked at his surroundings in a confident way, smiled at the bride sympathetically, and pronounced the words with clear and precise diction, hardly would we excuse him later if he claimed having done it all in a trance, unconsciously, proposing this as an excuse to cancel the effects of the wedding. I.e., what makes the illocutionary act a valid act is not the presence or absence of the intention of the agent, only known by himself and merely hypothesised by his hearers, but the way in which the act is performed in the social context, and the way it generates a legitimate uptake by its audience. Any alleged intention will have to rely on context features that are somehow observable by others, and could not only rely on a hidden state by the part of the speaker. 
But Alston denies this point categorically when he goes on shaping the example to his liking, turning it into something still harder to believe, since his case does not either involve the following feature:

(2) The groom mistakenly supposes himself to have called "time out", to have suspended the proceedings so that he could practice saying the fatal words, roll them over on his tongue, get the feel of them, before he actually did the deed. In that case we would all agree that he had not yet undertaken the marriage contract. If he had supposed himself to have called time out but had not gotten this across to the other participants, then the fact that he had made a stupid but honest mistake would shield him from any imputation of undertaking the marriage (Alston 2000: 140).

Once again, this would depend on the course of events: if immediately after uttering the words "Yes I do" the groom said "But no, no: do not misunderstand me, I was just rehearsing", we would probably be more prone to accept that he did make a very stupid mistake. But if he did not say anything else, and continued with the wedding, he could hardly adduce later that he was just rolling the words over in his tongue, as Alston claims. He did get married, and his words were the deed. It might have been true that he did not intend to get married while uttering his words, but he did get married anyway.

Now, Alston makes two claims about this final example that will help me point out the exact aspect of his theory that I don't find correct:

(1) We must not confuse the question of whether the groom purported to marry the bride, whatever his intentions, with the question of what illocutionary act would normally be attributed to him by those who witnessed the proceedings. Of course, everyone present would unhesitatingly take it that he had undertaken to marry the woman. But then they would have equally unhesitatingly taken it that he had intended to marry her. No one not privy to his secret intentions would have had the slightest doubt on either of these points until his later protestations. Since the confidence about what he is doing goes hand in hand with a confidence about his intentions we can't infer that the former is independent of the latter. Thus we can't infer that the spectators suppose him to have been undertaking to marry the bride, whatever his intentions (Alston 2000: 140).

Alston is correct here in noticing that there is some kind of non contingent relation between the effective occurrence of the illocutionary act and the attribution of illocutionary intentions to the speaker by the part of the audience. The utterance counts as an illocutionary act for the audience because the audience believes that, in performing that utterance in that context, the act is an expression of some quite specific intentions. If $\mathrm{x}$ counts as $\mathrm{y}$ in $\mathrm{C}$, it is because, for that audience, $\mathrm{x}$ legitimately counts as an expression of the intention to $\mathrm{y}$. It is here where the first and the second person perspectives can tell apart. The first person perspective is the one of the speaker; from his point of view, under normal conditions, he knows whether he had the intention to $\mathrm{R}$ or not. The second person perspective is the one of the audience, who is aware of the occurrence of utterance $\mathrm{x}$ in context $\mathrm{C}$, and correctly assumes that $\mathrm{x}$ in $\mathrm{C}$ counts as $\mathrm{y}$. In doing so, they attribute to $\mathrm{H}$ the intention to make $\mathrm{x}$ count as $y$. This is perfectly correct. What I would claim here is that the key to 
know whether the act took place or not is in this second person perspective- the one of hearers - not in the first person perspective - the one of the speaker. If the inferential basis for the audience is strong enough, that is, if it correctly justifies the attribution of the intention - something that could happen even if that attribution were wrong - the act actually happened - that is, Gazdar's function would apply, and the normative context would have effectively changed. In this respect, the first person perspective is not determinant to know if the act took place or notalthough it might be determinant to know if it was an intentional act or not.

Alston would disagree on this point. In his view, somebody "privy to his secret intentions" would have to assume that the speech act did not take place at all-e.g., because the groom thought that he had taken time off. But I would reply that even somebody privy to those hidden mental states would have to accept that the broom was getting married, even if he was not aware of that fact. The reason is that the performance of the act - the 'outer' utterance-was done in such a way that it was correct for the audience to assume it as an illocutionary act, precisely because they had no clue at all about the speaker's deviant intentions. It is true that the hearers' perspective was epistemically limited-i.e. they didn't know about the secret intentions of the speaker-; however, it is from this epistemically limited perspective where illocutionary adscriptions must always be made. The key to know if the act effectively took place is not to be found in that "privy" realm of the mind of the speaker, but in the public realm of social interaction. The performance of an illocutionary acts is not constitutively connected to the private and secret intentions of the speaker-as a set of states that we could only hypothetically infer from his behaviour - but to the set of criteria that are, and must be, shared by the users of language.

Those socially established criteria - an idea taken from Wittgenstein's later philosophy (see Navarro-Reyes 2010) - are logically good reasons for the attribution of intentions. By acting in a certain way-e.g., by uttering some particular words in a specific context-you give your audience a good reason to believe that you had some intention in performing those actions. And that reason is somehow good 'by definition': acting in such a way means that you have such and such intentions. However, even if their validity is a priori, criteria are defeasible. They are not infallible, and there might be an important ambiguity in their application; in those cases, we would probably give the speaker the benefit of the doubt about her own intentions. But if criteria are fulfilled up to a certain point, as they are in the situation Alston finally conceives, then the story leaves no room for ambiguity, and whatever the speaker later says about his own private states, his claims would just be out of order.

This is what happens in the final version of the story: an extremely odd and twisted case, after all the qualifications that Alston imposes on it-excluding trances or dazzling situations, time off taken by the groom, and so on. We are asked to envisage a person who realizes that, in his situation, if he utters 'I do' without any 
indication of a nonstandard use, he will be taken to have undertaken to marry the prospective bride. Realizing this, he says 'I do' without giving any indication of a nonstandard use, even though his intention is not to make the marital promise:

I find this incoherent as a description of a person in possession of his senses. I can make no sense of the idea that a person in full possession of his faculties, realizing that uttering $S$ will place him in a certain position, proceeds to utter $S$ in full awareness of what he is doing but without intending to place himself in that position. I would say that such a person has intentionally entered into the contract, whatever he may say later. With the constraints specified I don't know how to give a coherent description of the case except in those terms. [...] [This] is rather like jumping out of a seventieth-story window in full knowledge of what that means, but not be intending to kill oneself (Alston 2000: 141).

I think that what is perplexing for Alston is not that the imagined groom is irrational or inconsistent, but that the story itself is perfectly coherent with his own account. If the performance of the illocutionary act is strictly dependent on the causal role accomplished by the mental state of the speaker-his "privy" intention-, and this mental state is determined independently of any social criteria, his imagined Groom is perfectly conceivable: a person who would act according to social criteria up to point that would leave no doubts whatsoever about his own intentions... but would not have those intentions at all. What is odd in Alston's final case is that the groom has simply no public excuse of any kind but, in Alston's account, this situation does not prevent him from having the final and crucial excuse: that he simply did not intend to R, and he thus did not perform the illocutionary act at all.

The possibility of an unintended groom is an effect of Alston's reliance on private intentions, as a constitutive feature of illocutionary acts. And the way he tries to escape from this undesired consequence of this account is extremely disconcerting:

(2) We must also not identify the question of what illocutionary act, if any, he performed with the question of what conventional effect was generated. It is conceivable that the law should be such that when certain words are uttered (in the absence of certain kinds of defeaters such as coercion or mental incapacity) the utterer has taken on certain obligations and this consequence might hold regardless of what is the correct illocutionary description of his activity (Alston 2000: 139).

By telling illocutionary acts apart from their conventional consequences, Alston assumes a cost that is much higher than he is willing to accept. Gazdar's initial description of what a speech act is, for instance, would not work, since it could be the case that we had the function from one normative context to another just with the utterance. If Alston were right, we would be forced to say something like that the broom is married, even if he never got married; or that the promise was made, even if the speaker did not make any promise; or that the full English breakfast was ordered, even if nobody ordered it. What we find here is the phantom that haunted Austin: a view in which the performance of the speech act would take place in the hidden and private space of the soul of the utterer, where the words he uttered ex- 
ternally would be nothing but fallible and contingent symptoms of a sort of spiritual, inner event. Alston's imagined broom is finally no one else but Hippolytus.

Once he has rejected those cases of unintentional speech acts as marginal, unimportant, and probably even contradictory, Alston considers the possibility of transforming his own account in such a way that even those cases would have their place:

But if we do recognize unintentional illocutionary acts, how could they be treated in my theory? [...]

We can define a variant of ' $R$ '; call it 'R-U' (' $U$ ' for 'unintentional'). If R'ing that $\mathrm{p}$ is deliberately putting oneself in such a position that one is subject to correction in case of not-p, then R-U'ing that $p$ is being in such a position by virtue of one's utterance, though not by deliberately putting oneself in that position. By substituting ' $R-U$ ' for ' $R$ ' throughout we can transform any analysis of an illocutionary act concept into an analysis of a concept that applies indifferently to intentional and unintentional performances. The concept of being in the relevant normative position by virtue of uttering $\mathrm{S}$ will be the concept of, for example, promising to do D, whether intentionally or unintentionally.[...]

I could rewrite all the analysis schemata in this form, and if I felt that unintentional illocutionary acts were of sufficient importance I would do so. But since they are at worst nonexistent and at best of marginal importance, I do not choose to proceed in this way (Alston 2000: 141-2).

The problem with this last twist in the argument is that changing $\mathrm{R}$ for $\mathrm{R}-\mathrm{U}$ in the whole analysis would not just be a modification of the original version, but a simple rejection of it, since the change would affect Alston's original definition of illocutionary act. He had said that an illocutionary act essentially is a sort of intentional act — not a matter of the utterer's recognizing an already existing state of affairs, or assuming it — whereas at the end we would have the possibility of a genuine speech act, with legitimate normative implications, that is not intentional at all. This step would not just introduce a minor change in the theory, as Alston seems to believe. On the contrary, the whole house of cards was standing on this single claim: that the illocutionary act is what it is because the speaker intends it to be so.

Alston refusal to introduce this final change in his analysis is explained by his disdain for those marginal cases - unintentional illocutionary acts-whose unimportance would not make it sensible to alter the whole system. But it is not laziness what prevents Alston from taking that step: it is architectural prudence. If we took this last idea seriously, we would have to tell the speaker's intention to $\mathrm{R}$ apart from the correct illocutionary description of his action; and, as we saw before, we would also have to tell the correct illocutionary description of the action apart from the social normative effects that it would have. In other words: we would have to assume the whole collapse of Alston's theory. 


\section{Conclusion: the second person perspective}

With this long discussion of Alston's views I have tried to argue in favour of two thesis that are opposed to the ones that he defends:

a) The discussion about unheard speech acts showed us that illocutionary effects - and thus the very performance of the illocutionary act - is constitutively dependent on the audience's uptake. An unheard speech act would not be a kind of speech act-since those utterances would not produce any change in the normative context.

b) The discussion about unintended speech acts proved that what makes the utterance count as a speech act is the legitimate attribution of intentions to the speaker by the part of her hearers. This legitimacy could fail, since it has to be done from a perspective which is always epistemically limited - the one of the audience. That makes it is perfectly possible to conceive unintended speech acts as a legitimate cases of speech acts-i.e., as effective changes in the normative context. From this point of view, unintended speech acts would be a legitimate category within speech acts tout court.

In other words: by claiming that a speech act was unheard we would imply that it never took place as a speech act; whereas by claiming that a speech act was unintentional we would be qualifying the kind of speech act that did effectively take place.

I agree with Alston on the idea that there is no way to understand the working of speech acts without taking the idea of responsibility as a key point. But what is needed is not Alston's conception of R'ing, as the intentional act by which the speaker makes herself responsible for her words. I would say that responsibility shows up later: with the uptake. I am not responsible for what I meant, or for what I intended to do with my words, but for what actually I did, and for the set of legitimate expectations that my words produced in those who received them. What I have to answer for are my words, not my privy intentions.

I have not been trying to prove that illocutionary intentions are superfluous in an account of speech acts. On the contrary: the legitimacy of the hearer's detection of speech acts performance rely on criteria that are about these intentions. If we took intentions simply out of the story we would be throwing the baby away, together with the bath water. It is crucial for our illocutionary practices that utterances fulfil criteria for the attribution intentional states, and if they did not, then the practice would loose its meaning. But what is true for the practice does not have to be true for each and every performance within that practice. It is true that promises cannot be defined as a type of speech act unless we take into account what the normal intentions of promisors are. But the definition of a token promise, that is, our understanding of what the very occurrence of each and every promise is, cannot depend on the existence of those intentions in the privy realms of promisors, since otherwise we would be blind in the adscription of illocutionary acts to others. 
It finally results that the only way to force Hippolytus to keep his word is by appealing to his words themselves, not to his privy intentions, or to his putative assumption of responsibility for them. Illocutionary acts do not hold up because we make ourselves responsible for what we do while we are doing it, but because others make us responsible for what we have done, once we have done it. The authority to say if an act was intentional or not might be found in the first person perspective; but the authority to say if the act itself took place-whether intentionally or not-must rely somewhere else: in the perspective of the second person, precisely because it is epistemically limited.

\section{References}

Alston, William P. (2000). Illocutionary Acts and Sentence Meaning. Ithaca: Cornell University Press.

Austin, John L. (1962). How to do things with words. Ed. J. O Urmson. Oxford: Clarendon Press.

Gazdar, Gerald (1981). "Speech act assignment". In A. K. Joshi, B. L. Webber \& I. A. Sag (eds.), Elements of Discourse Understanding (64-83). Cambridge: Cambridge University Press.

Harnish, Robert M. (2009). "Internalism and Externalism in Speech Act Theory". Lodz Papers in Pragmatics, 5:1, 9-31.

Moya, Carlos J. (1990). The Philosophy of Action: an Introduction. Oxford: Polity-Blackwell.

Navarro-Reyes, Jesús (2010). "Speech Acts, Criteria and Intentions". Lodz Papers in Pragmatics, 6:1, 145-170.

Searle, John R. (1969). Speech Acts: an Essay in the Philosophy of Language. Cambridge: Cambridge University Press.

Sperber, Dan \& Wilson, Deirdre (1986). Relevance: Communication and Cognition. Oxford: Blackwell.

Strawson, Peter F. (1964). "Intention and Convention in Speech Acts". The Philosophical Review, 73:4, 439-460. 